\title{
Characteristics of the Wooden Structures and Elevation of Central Halls in Korean Buddhist Temples with a Side Location Altar
}

\author{
Dai Whan An
}

Assistant Professor, Department of History, Sunmoon University, Korea

\begin{abstract}
When Buddhism was introduced into Korea, the altar was located in the center of the Buddhist hall, and stayed there for a long time. However, the location of the altar eventually moved to the back of the hall as time went on. As for the planar structure of the hall, there are 5 exceptions where altars were situated on the far side of the hall, so that an asymmetrical space was created while wooden structures had an influence. The 5 halls investigated here can be classified into types in terms of whether their wooden structure and the elevation are symmetrical or asymmetrical. In the asymmetrical type, a part of the upper structure, floor structure, column arrangement, and window arrangement show asymmetrical features.

In conclusion, first, as the location of the altar was moved to the side of the hall, it induced alterations such as a planar plan, structure, window arrangement and type of roof. Second, as the construction plan of the hall was initiated, asymmetrical structural features were considered. Third, asymmetrical features were used as a method to achieve effective spatial use of part of the altar and worshippers.
\end{abstract}

Keywords: central hall of Buddhist temple; location of the altar; wooden structure; elevation; asymmetry

\section{Introduction}

\subsection{Background and Purpose of Research}

In the Buddhist temples of Korea, the central hall enshrines the statue of Buddha and the altar and, being the place where Buddhist rituals are performed, is the most important building within each temple. It was common to enshrine the Buddha statue in the center of the hall ${ }^{1)}$, towards the front. In other words, just as the hall is the center of the temple, the statue of Buddha occupies the spatial center of the hall.

Historically, the interior of the hall has shown a tendency to change in specific directions. This began with the increasing importance of the area in front of the altar ${ }^{2}$ as a space used by people. Thus, the interior of the hall has changed from a statue-oriented space to a people-oriented space. The most noticeable change has been the tendency to expand the area in front of the altar to allow more space for use by people. To permit expansion, the altar was often moved from the center to the rear, or to the side of the hall. The change in altar location affects the structure ${ }^{3)}$ of the hall and ultimately results in holistic changes to the hall's architecture ${ }^{4)}$.

*Contact Author: Dai Whan An, Assistant Professor, Department of History, Sunmoon University, 70 Sunmoonro 221, TangjungMyun, AsanSi, Chungnam, 336-708, South Korea Tel : +82-10-2757-4229 Fax: +82-70-8883-4229

E-mail: archira91@hotmail.com

(Received April 10, 2013 ; accepted February 26, 2014)
Among the 165 Buddhist temples designated as cultural properties, the front of the altar faces the same direction as the hall facade in 160 of them.

In only five of the temples, the altar is located to one side of the hall, with the front of the altar facing the side. These halls have various wooden structures and elevations without fixed rules. Some of these halls show asymmetry in the structure and the elevation when seen from the front. Namely, some of them show asymmetry with respect to the longitudinal section as a plane of the symmetry. Therefore, when the asymmetrical areas are examined, the influence of altar movement on hall construction can be understood. In addition, as the front of the altar and the hall are facing different directions, the effect of altar direction on the hall can also be examined.

This study aims to examine the architectural characteristics of halls in which altars are located to one side. Furthermore, it aims to examine the effect of altar movement on hall construction planning.

\subsection{Research Method and Scope}

Among the 165 halls designated as cultural properties, five halls with altars located to one side were chosen as research subjects. These are the Muryangsujeon Hall of Buseosa temple(浮石寺 無量壽殿), Daeungjeon Hall of Gosansa Temple in Daejeon(大田高山寺大雄殿), Daegwangbojeon Hall of Magoksa Temple( 麻谷寺 大光寶殿), Daeungjeon Hall of Bulgapsa Temple( 佛甲寺 大雄殿) and Daeungjeon Hall of Tongdosa Temple( 通度寺 大雄殿). 
Table 1. The Symmetrical Characteristics of the Buddhist Hall where the Altar is Facing the Front ${ }^{5)}$

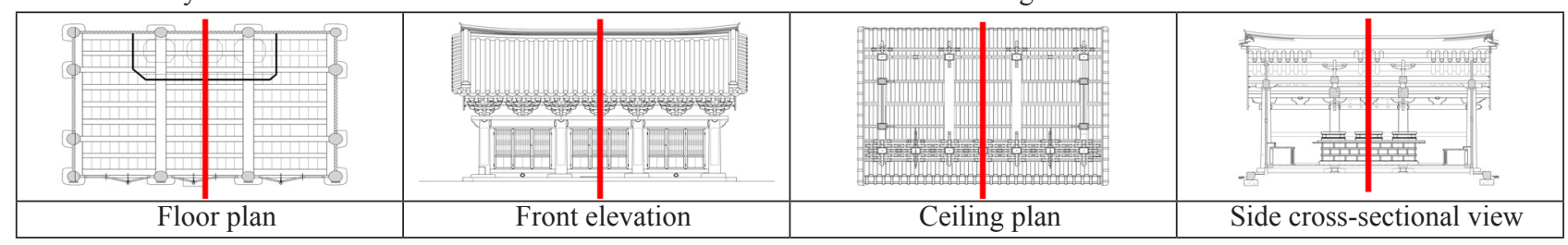

The structure and elevation of these halls will be examined to categorize them as symmetrical or asymmetrical and compared on the left and right side of the hall when seen from the front of the hall. In detail, column, daeryang (main girder: 大樑), toeryang (rear girder: 退樑), chungryang (cross girder: 衝樑), and beam frame arrangement of the floor were considered the main elements of the structural composition, while the stairs, door, windows, and roof form were examined concerning elevation, entrance to the hall and outer events in front of the hall.

At first, the symmetry of the hall is examined according to whether the direction of the altar corresponds to the direction of the hall to find the basic characteristics of the hall with a side located altar. Secondly, each research subject is analyzed to examine asymmetrical areas. Finally, the author examined the significance of the asymmetrical areas that appear simultaneously in the structure and elevation of halls with altars located to one side.

\section{Characteristics According to Direction of Hall and Altar}

2.1 The Direction of the Hall and Altar Correspond

In these temples, the altar location is either the center or the rear of the hall. In the latter, changes to architectural elements occurred in accordance with the movement of the altar towards the rear, as can be seen in the longitudinal section and side of the hall. However, when seen from the front, the architectural elements are symmetrical, and it is difficult to notice changes to architectural elements resulting from the movement of the altar ${ }^{6}<$ Table 1.>.

There are various advantages to having the direction of the altar correspond to that of the hall. First, as the hall and altar can be seen while entering, religious awe can be evoked. Second, emphasizing the front of the altar has the same effect as emphasizing the statue of Buddha, heightening people's concentration on the building and statue. Therefore, the design of the front can be more heavily emphasized compared with the other sides. Third, the structure becomes symmetrical, which means that the load of the upper structure can be effectively conveyed to the structure below. Fourth, when holding large-scale outdoor events in the yard in front of the hall, the front of the statue of Buddha can be faced to create a sense of centrality.

One possible disadvantage is that the altar is located on the long side of the hall, and there may be relatively less concentration on rituals towards the Buddha statue $^{7}$. In most halls, however, the altar and hall face the same way because the advantages outnumber the disadvantages.

\subsection{The Altar is Located to One Side of the Hall}

When the altar is located to one side of the hall, it is skewed to one side of the hall when seen from the front and faces towards the side of the hall. So, the hall is not symmetrical when seen from the front.

The characteristics that appear in all five of the halls are as follows. First, the front of the hall is viewed while entering. However, the side of the skewed altar is seen while entering, which results in visual asymmetry. Second, the interior of the hall becomes asymmetrical, as it is divided into the area where the altar is located and the area where rituals are performed. Third, when there are outdoor events in the front yard, the events are conducted facing the side of the statue of Buddha. In other words, rituals are performed towards a Buddha statue that has 'turned its back.' Therefore, in outdoor events performed in the front yard, there is relatively less concentration on the statue of Buddha.

Among the five halls, only a few showed asymmetry in the structure and elevation. It can be seen that the structure and elevation were not planned in accordance with certain fixed rules, as the altar was positioned to one side of the hall. Therefore, different degrees of influence of altar location on structure and elevation can be identified through the asymmetrical areas seen from the front of the hall.

The advantage of halls with an alter located at the side is that the altar is located on the shorter side. Thus, when there are rituals conducted in front of the altar, concentration can be heightened in this space. However, this seems to have only been applied in a few halls due to the aforementioned advantages of having the altar and hall face the same direction.

\section{Case Analysis of Halls with Altars to One Side}

The outline of individual halls is examined, and asymmetrical features of the structure and elevation when seen from the front are investigated.

\subsection{Muryangsujeon Hall of Buseoksa Temple}

This hall was rebuilt in 1016 and renovated in 1376, and it is one of the oldest wooden buildings.

This hall faces south, and the altar is located on the west side of the hall, facing east. It is known to express the doctrine of the 'Western Paradise (西方淨土)' Inside, it enshrines the Amitabha Buddha. The size of the hall is $5 \mathrm{kan}$ (間) to the front and $3 \mathrm{kan}$ to the side. The area is $216 \mathrm{~m}^{2}$, with a front length of $18.75 \mathrm{~m}$ and side length of $11.52 \mathrm{~m}$. The structural composition consists of 2 high columns and 9 purlins. The brackets 
Table 2. Muryangsujeon Hall of Buseoksa Temple

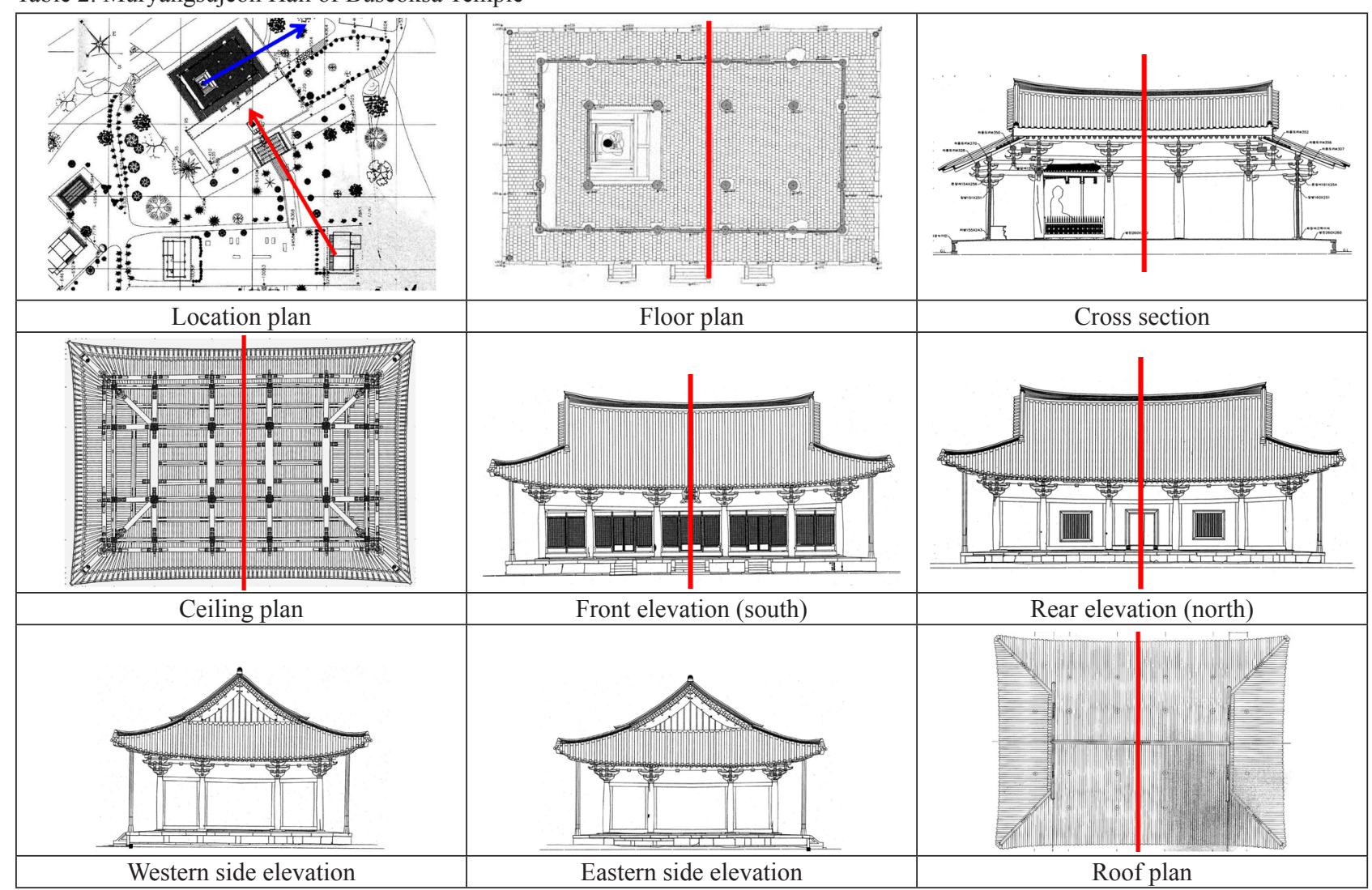

（栱包） are in jusimpo form (柱心包), and the roof is a gambrel roof.

In the front, a lattice door was installed, while in the central kan of the rear, a panel door was installed. In the kan between the columns to the left and right of the center of the building, a grill window was installed, and panel windows were attached over it on the inside. The entrance stairs were installed in the front central kan and in the kan next to the center of the building.

When seen from the front, the entire structure and elevation are symmetrical, other than the altar being skewed to one side of the hall and the subsequent asymmetry in the interior. Therefore, this hall is considered to be the least influenced by the change in altar location.

\subsection{Daeungjeon Hall of Gosansa Temple}

This hall was reconstructed in 1636. The hall faces south-east, and the altar faces north-east; hence, it expresses the doctrine of the 'Western Paradise.' Inside, it enshrines the Sakyami Buddha. The size of the hall is $3 \mathrm{kan}$ to the front and $3 \mathrm{kan}$ to the side. The area is 50.6 $\mathrm{m}^{2}$, with a front length of $8.65 \mathrm{~m}$ and side length of 5.85 $\mathrm{m}$. The structural composition is 5 purlins, without any high columns. The brackets on the columns are in dapo form (多包), and the roof is a gable roof. In front of the hall, there are slender-ribbed doors in the central kan and the adjacent kans. On the eastern side, an entrance door is in the front adjacent kan area. No doors or windows were installed in the rear or western sides. Wide stairs were installed in the front, and the stone platform has only one layer.
When seen from the front, the asymmetrical element is that there is an entrance door on the eastern side of the hall. It seems to have been installed on the eastern side because the altar is located on the western side. However, even in temples in which the hall and altar face the same direction, there are many cases where doors have been installed on one side for entry and exit. Therefore, it is difficult to conclude that the door was built on one side because of the altar's location on the other side of the hall.

\subsection{Daegwangbojeon Hall of Magoksa Temple}

This hall was constructed in 1650. Since then, there have been repeated episodes of loss, reconstruction, and repair. The hall faces south, and the altar is located on the western side, facing east. Inside, it enshrines the Variocana Buddha.

The size of the hall is $5 \mathrm{kan}$ to the front and $3 \mathrm{kan}$ to the side. The area is $160.79 \mathrm{~m}^{2}$, with a front length of $18.61 \mathrm{~m}$ and side length of $8.6 \mathrm{~m}$. The brackets (栱包) are in dapo form, and the roof is a gambrel roof.

The asymmetrical areas found in the structure are as follows.

(1) Internal column ( 內柱): There are three columns on the eastern side, which is the area people use, and two on the western side with the altar. On the side of the hall that people use, there are two columns towards the rear and one towards the front. On the altar side, there are two columns installed at the rear of the altar.

(2) Daeryang (大樑): There is no daeryang above the second column row-in other words, the location of the altar and baldachin (the canopy above the Buddha 
Table 3. Daeungjeon Hall of Gosansa Temple in Daejeon

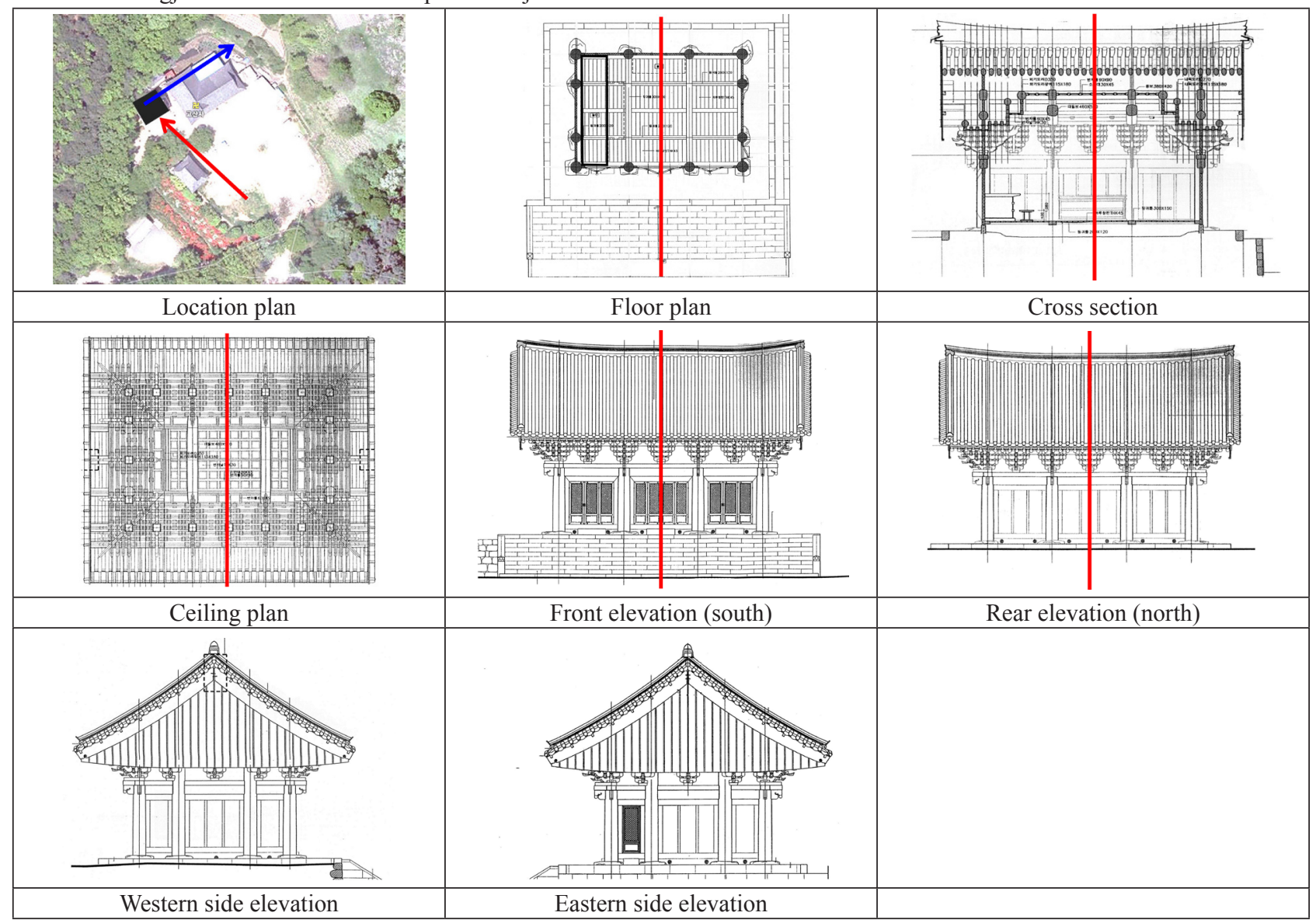

statue). The daeryang on the third column row from the east consists of a single member from the front to the rear of the hall, and it has the largest cross area. The daeryang on the fourth column row from the east extends from the front to the column just in front of the farthest column from the back, and it has the second largest cross-sectional area. The daeryang on the fifth column row from the east is a member that extends from the column just in front of the farthest column in the front to the column just in front of the farthest column in the back, and it has the smallest cross-sectional area.

(3)Toeryang (退樑): On the second column row from the east, there is a toeryang on both the front and rear sides. There is no toeryang on the third column row from the east. On the fourth column row from the east, there is a toeryang only on the rear side of the hall. On the fifth column row from the east, there is a toeryang on both the front and rear sides.

Regarding elevation, the asymmetrical part is the stairs. There are stairs at the front central kan and the eastern central kan. Stairs were installed on the eastern central kan seemingly to allow entry on the side that people use.

In conclusion, there are many asymmetrical features in the structure, but regarding elevation only the stairs appeared to be asymmetrical.

\subsection{Daeungjeon Hall of Bulgapsa Temple}

This hall is believed to have been built in 1635 . Despite reconstruction since then, its appearance has been essentially unaltered since the 17 th century. According to a repair report for this hall, the altar was located to one side of the hall from 1765 to 1825 and from 1987 to the present. However, records indicate that from 1825 to 1987 , the altar faced the front of the hall. ${ }^{8)}$ Thus, it serves as a useful subject for this analysis in that factors regarding the adjustment of altar location can be examined.

In contrast to the Muryangsujeon Hall of Buseoksa temple, this hall faces west, and the altar is on the north side, facing south. Therefore, it does not follow the doctrine of the 'Western Paradise.' Inside, it enshrines the Sakyami Buddha. The size of the hall is 3 kan to the front and 3 kan to the side. The area is $82.98 \mathrm{~m}^{2}$, with a front length of $11.14 \mathrm{~m}$ and side length of $7.44 \mathrm{~m}$. The brackets on the columns are in dapo form, and the roof is a gambrel roof.

The asymmetrical areas found in the structure are as follows.

(1) Internal column: In the northern part, where the altar is located, there are four columns arranged around the altar, but there are no columns in the south, which is the area that people use.

(2) Daeryang: There is no daeryang in the second column row from the north above the altar and baldachin, but there is one on the third column row from the north.

(3) Toeryang: In the second column row from the north, there is a toeryang in the front and rear of the hall. However, there is no toeryang on the third row from the north. 
Table 4. Daegwangbojeon Hall of Magoksa Temple

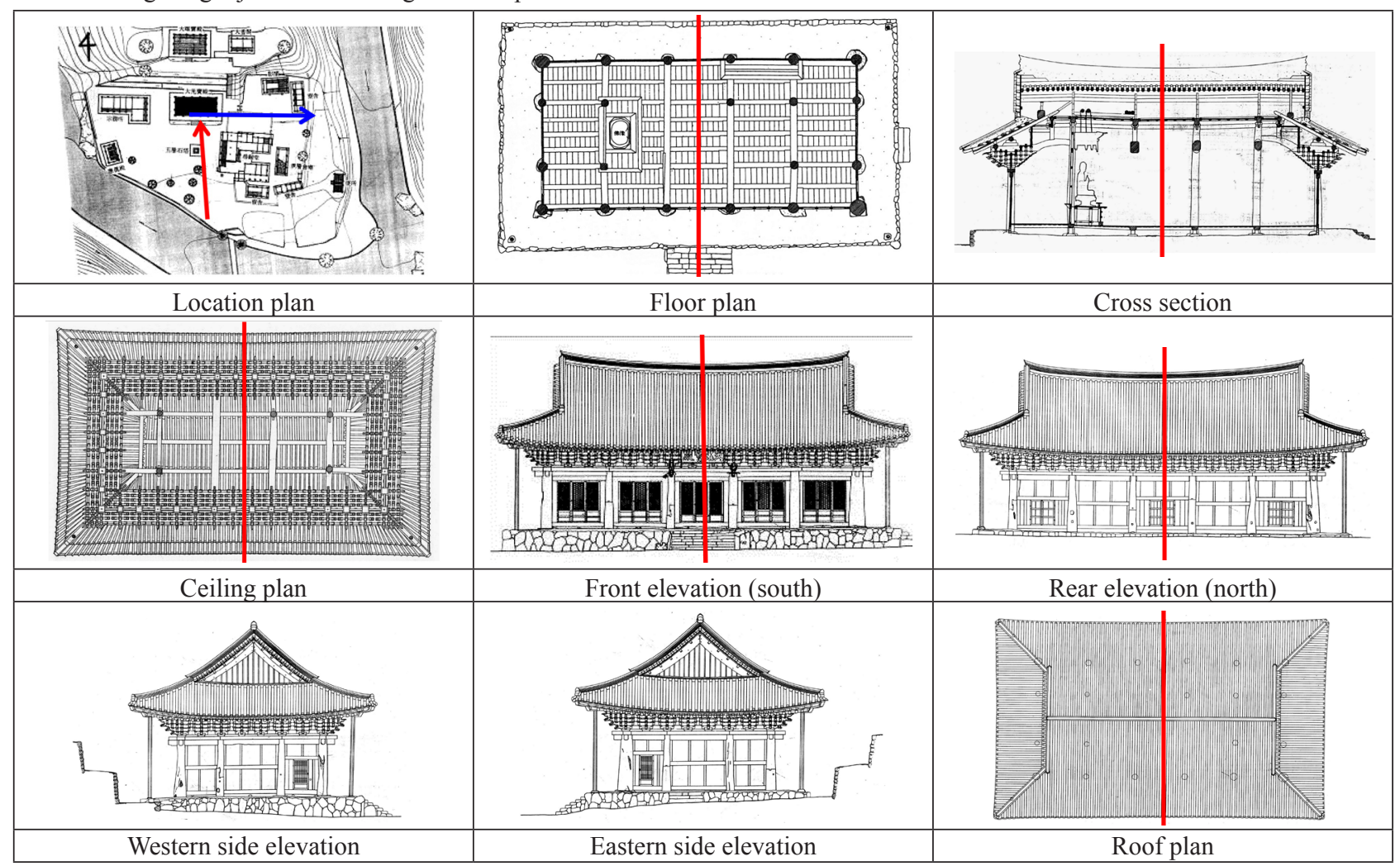

(4) Chungryang (衝樑): There is no chungryang on the northern side, but there is one on the southern side.

(5) Floor frame: There are two long frames installed inside the hall from the front to the rear. The long frame on the northern side in front of the altar has a smaller cross-sectional area than the long frame on the southern side. The cross-sectional area is small, as the long frame in front of the altar is divided by columns, resulting in shorter length.

The asymmetrical features regarding elevation are as follows.

(1) On the southern side, which is the front of the hall, a large main door with flower patterns was installed in the central kan and adjacent kan.

(2) There are no doors or windows to the north, which is the rear side.

(3) On the western side, where the altar is located, a large main door with flower patterns was installed only in the central kan.

(4) On the eastern side, which is the area used by people, there is a large main door in the central kan and cross-ribbed window in the adjacent kan.

Therefore, there was a tendency to have a small number of undecorated doors or windows on the same side as the altar, but a large number of decorated doors or windows on the side facing the altar. On all sides except the front, the stone platform was low, enabling entry without stairs, and stairs were built only on the front central kan, creating symmetry.

\subsection{Daeungjeon Hall of Tongdosa Temple}

This hall was expanded in 1644. It faces east, and the altar is located on the northern side, facing south; thus, it does not express the doctrine of the 'Western Paradise.' Because a window was installed facing the keumkanggyedan ( 金剛戒壇), rituals are performed towards the keumkanggyedan. Therefore, inside the hall, there is only an altar and no statue of Buddha. Thus, this hall is a unique structure as it is considered to be in the same domain with keumkanggyedan.

The size of the hall is $5 \mathrm{kan}$ to the front and $3 \mathrm{kan}$ to the side. The area is $175.4 \mathrm{~m}^{2}$, with a front length of $15.83 \mathrm{~m}$ and side length of $11.08 \mathrm{~m}$. The brackets on the columns are in dapo form, and the roof is T-shaped, which is unusual.

The asymmetrical areas found in the structure are as follows.

(1) Internal columns: On the northern side, where the altar is located, there are two columns arranged in front of the altar. On the southern side, the area that people use, there are two columns on the eastern side and no columns on the western side. The method of arrangement is identical to that of Daegwangbojun Hall of Magoksa temple.

(2) Daeryang: There is no daeryang in the second column row from the north above the altar, but there is two on the third and fourth column row from the north in an east-to-west direction. On the northern side, there are two daeryang in a north-to-south direction, perpendicular to the other daeryang.

(3) Toeryang: There is one on the southern side and three towards the rear (western side).

(4) Chungryang: There is one on the southern side and two on the second column row from the north. 
Table 5. Daeungjeon Hall of Bulgapsa Temple

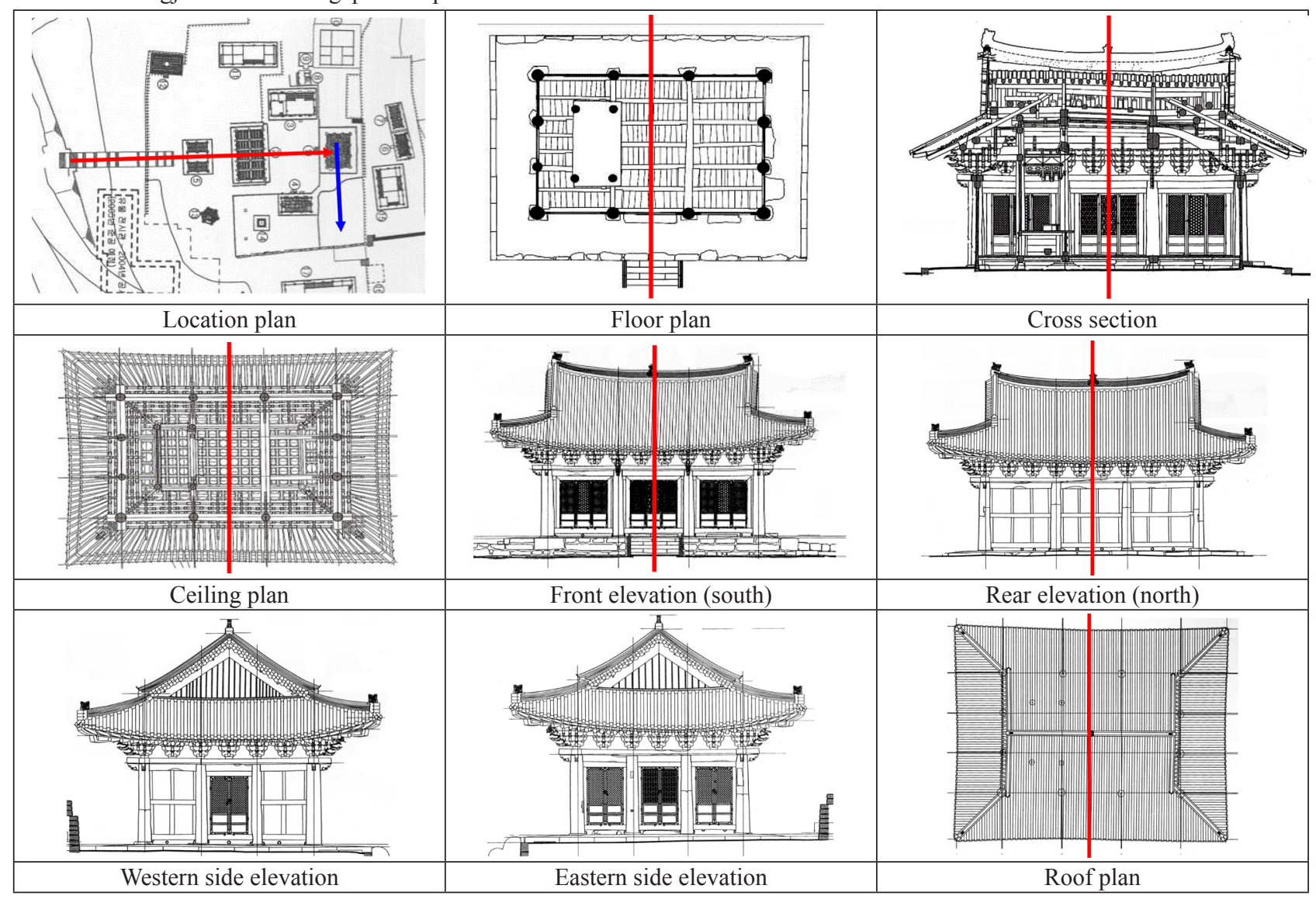

(5) Floor frame: The frame arrangement is different on the northern and southern sides of the hall, and the direction of the floor boards also differs accordingly. On the northern side, the large, main floor frame was installed in a south-to-north direction, whereas on the southern side, the large, main floor frame was installed in an east-to-west direction.

The following asymmetrical features can be found with regard to elevation.

(1) The front (eastern) door and windows are installed across 5 kans. However, in the rear (western side), only 3 kans from the south are installed with a door and windows. Doors and windows were not installed on the kan with the altar, nor on the adjacent kan, as these consist of walls.

In other words, the northern side, where the altar is located, has fewer doors or windows, and doors and windows were mainly constructed on the southern side, which is the area that people use and toward which the altar faces.

(2) On the southern side, there are stairs in the central kan, whereas there are none on the northern side.

(3) On the western side, there are no stairs in the central kan but in the southern adjacent kan. On the eastern side, there are small stairs at the end of the southern stone platform. Therefore, it is evident that stairs were installed with the aim of emphasizing spaces used by people.
(4) The roof forms a T-shape, where the ridges of the roof are gathered towards the north; this creates asymmetry when seen from the eastern side (the façade), but it is symmetrical when seen from the southern side. In conclusion, this hall is characteristic in that it forms asymmetry in both structure and elevation.

\section{Types in Accordance with Symmetry 4.1 Types and Characteristics of Structures}

The composition of structures is directly related to the location of the altar and the use of the interior. In this respect, the shared characteristics when the structure is symmetrical or asymmetrical are examined. (1) Symmetrical when seen from the front

The structures of Muryangsujeon Hall of Buseoksa temple and Daeungjeon Hall of Gosansa temple are symmetrical when seen from the front. One shared characteristic of these halls is that, because only the altar has moved to the side, the location of the altar is fluid. Thus, they have similar structures to those of halls in which the altar and hall face in the same direction. Therefore, the load of the upper roof and structures can be conveyed evenly below, and structural stability is considered to be relatively higher compared with asymmetrical types.

Hence, regarding spatial use, the altars in these halls have been moved to the side to heighten the practicality of the space for rituals. 
Table 6. Daeungjeon Hall of Tongdosa Temple

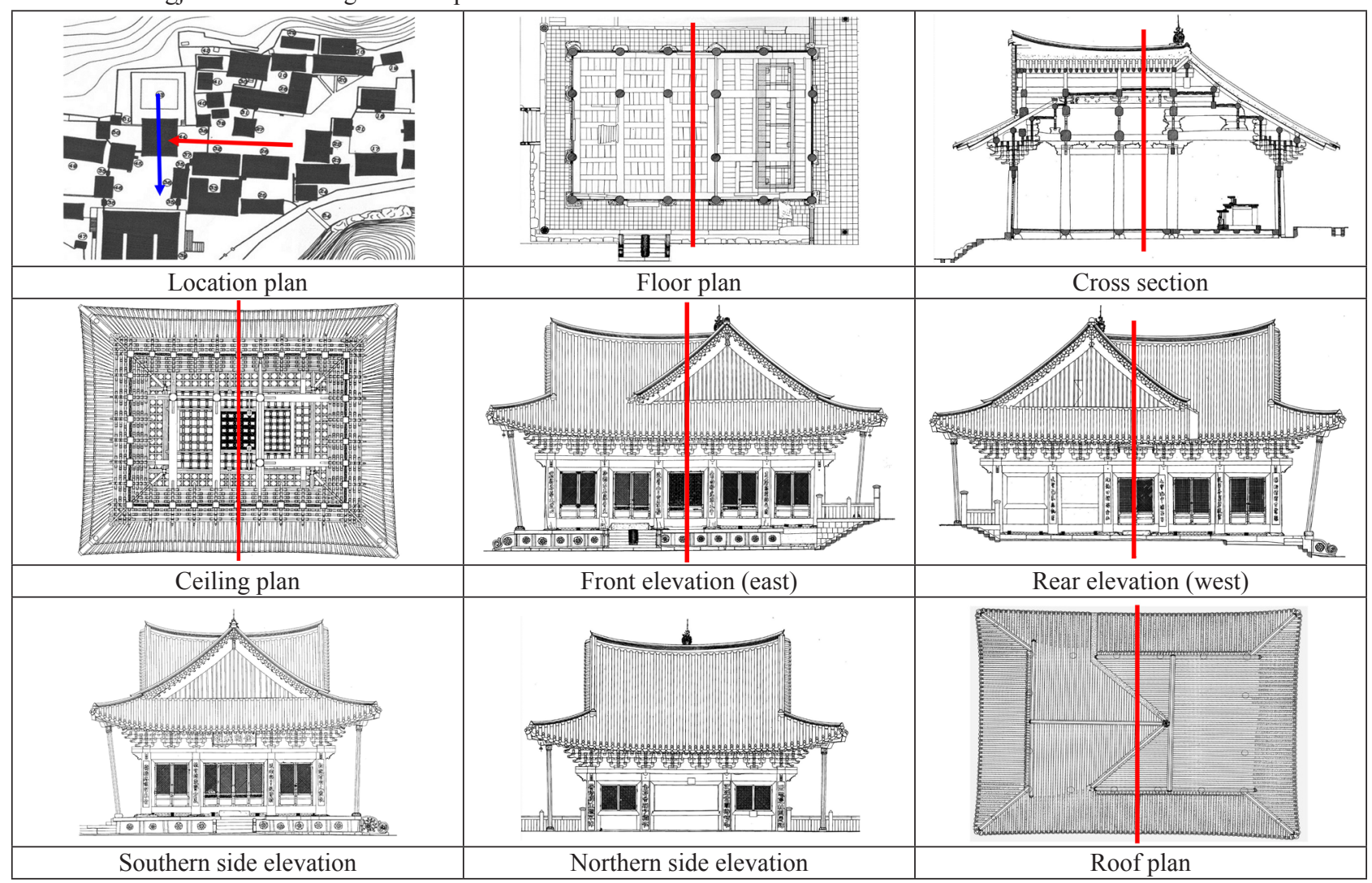

(2) Asymmetrical when seen from the front

The structures of Daegwangbojeon Hall of Magoksa temple, Daeungjeon Hall of Bulgabsa temple, and Daeungjeon hall of Tongdosa temple are asymmetrical when seen from the front.

The common characteristic of the structures of these halls is that they were constructed to maximize the practicality of the interior space. When the space used by people is examined, the space was made to appear larger through removal of the columns in the entrance area. Because the upper structure was constructed in a similar manner to halls with altars at the center, there is a sense of stability when using the hall. Major members with large cross-sectional areas were used, such as the daeryang to supplement the areas without columns; this has the effect of making the upper structure seem lower. On the other hand, when the space with the altar is examined, Daegwangbojeon hall of Magoksa temple did not omit the column, and Daeungjeon hall of Bulgapsa temple and Daeungjeon hall of Tongdosa temple added a column at the front of the altar, giving the appearance of guarding the altar. The upper structure in Daeungjeon Hall of Bulgapsa temple and Daegwangbojeon hall of Magoksa temple omitted members with large cross-sectional areas, such as daeryang and chungryang, and in Daeungjeon hall of Tongdosa temple, the direction of the structure changes, with no daeryang passing above the altar. In other words, it is typical to create a high space by having no large members passing through the upper structure above the altar.
Overall, the spaces used by people were made lower and wider, while the spaces with altars were made narrower and higher. Thus, it is evident that the column arrangement and member composition of the upper structures were considered along with the location of the altar during hall planning.

Because halls with asymmetrical structures are not able to convey the load of the roof and upper structure evenly to the lower structures, there is less structural stability. It can be presumed that halls with altars to one side were built less frequently due to these structural problems.

\subsection{Types and Characteristics of Elevation}

Elevation involves the characteristics of outdoor space usage as well as use of the interior. In this respect, the shared characteristics when the elevation is symmetrical or asymmetrical are examined.

(1) Symmetrical elevation

When seen from the front, Muryangsujeon hall of Buseoksa temple is symmetrical in the entire elevation, while Daegwangbojeon hall of Magoksa temple is asymmetrical in only its eastern stairs. Daeungjeon hall of Gosansa temple is asymmetrical in only its eastern entrance, while all other areas are symmetrical. In the case of Daegwangbojeon hall of Magoksa temple and Daeungjeon hall of Gosansa temple, these characteristics are commonly seen in halls in which the altar and hall face the same direction; thus, the asymmetrical elements in elevation cannot be understood as arising from the location of the altar. Therefore, when seen from the outside, it is not evident 
whether the altar is facing the front or toward one side of the hall. From the outside, the location of the altar is only known when the door of the hall is opened. In addition, in terms of arrangement, these halls do not have outdoor spaces in which to perform events towards the front of the hall. Only when outdoor events are performed or people go toward the hall, they can recognize the asymmetrical situation.

Therefore, these halls have the disadvantage that it is very difficult to conduct outdoor events facing the front of the statue of Buddha. During the late Joseon dynasty, especially, when outdoor events were expanded, this would have been a fatal disadvantage.

(2) Asymmetrical elevation

Daeungjeon hall of Bulgapsa temple and Daeungjeon hall of Tongdosa temple are asymmetrical in elevation when seen from the front of the hall. When the common characteristics of these halls are examined, the elevations on the front side and on the side faced by the altar are constructed similarly; decorative doors and windows are installed to allow an opening on the side of the hall faced by the altar. In addition, stairs are installed. However, the side where the altar is located is relatively closed, as the number of doors and windows is reduced and decorations are minimized.

In this way, a feeling of openness characterizes the side faced by the statue of Buddha. And, the location of the altar can be recognized from outside the hall and can affect the spatial orientation of the ritual. As mentioned before, when outdoor events were held in the space in front of the hall, there was the disadvantage that rituals had to be performed while viewing the side of the statue of Buddha. To compensate, the direction faced by the statue was opened up, and a small space was made on one side of the hall so that small-scale outdoor events could be performed.

\section{Conclusion}

Until the early period of the Joseon dynasty, positioning the altar to one side of the hall was used as a method to secure space in front of the altar. Currently, five halls with altars to one side remain, and these have various kinds of structure and elevation; hence, the types were categorized.

Types that have a symmetrical structure were built according to construction plans nearly identical to those of halls with altars facing the front of the hall; hence, it is evident that adjusting the location of the altar is not difficult. So, the location of the altar can be understood to have little influence on architectural elements. In asymmetrical types, however, there is evidence that consideration was given to the positioning of the altar to one side from the initial stages of planning. To maximize the effectiveness of the interior space, there was differentiation between the upper structures of the area with the altar and the area used by people. However, because the load of the roof and upper structure is unevenly conveyed, the asymmetrical structure has relatively less structural stability than the symmetrical structure.

For types with symmetrical elevation, it was hard to discern the location of the altar from the outside, and outdoor events had to be conducted while viewing the side of the statue of Buddha. However, in the asymmetrical type, the location of the altar could be perceived from the outside, and the aim, evidently, was to open up the side faced by the altar.

Overall, halls with altars to one side were practical for using the interior space, but certain aspects of the structure and outdoor space usage were inefficient. Such halls were used only until the mid-Joseon dynasty and then fell out of use.

\section{Acknowledgements}

The early draft of this paper was presented at the 'Proceedings of Region IV (Asia and Oceania) UIA 2010 International Symposium on the conservation of Architectural Heritage', China, and the author wishes to thank Sung-Woo, Kim Professor of Yonsei University for his help in producing the proceeding paper.

\section{Notes}

1 'Hall' means central hall in the Buddhist temple in this study.

The altar addressed in this study refers to a main altar on which a statue of Buddha is placed. Auxiliary altars are located on the right and left sides of the main altar.

3 'Structure' means wooden structure.

4 There are two types of Buddhist ceremony. One is performed with people circling around the altar and the other is performed in front of the altar. As time passed, the latter was emphasized.

5 The red line means the plane of symmetry when seen from the front of the hall.

6 The study of Dai Whan An is Reference 2).

7 When the altar is located on the long side of the hall, fewer people are able to face directly towards front of the altar, and more must face toward its side, compared with when the altar is located on the short side of the hall.

8 A report on the repair of Daeungjeon Hall of Bulgapsa temple, 2004.

\section{References}

1) Sang-Hyeon, Kim (1997) A study on the organization of the floor plan and position of the altar in a Buddhist sanctum. Master Dissertation, Department of Architectural Engineering Graduate School of Yeung Nam University.

2) Dai-Whan, An (2011) The relationship and it's change between location of Altar and Wooden structure of central halls in Korean Buddhist temples. Doctoral Dissertation Department of architectural Engineering Graduate School of Yonsei University.

3) Ministry of Culture (2002). Actual Survey Report of Muryangsujeon Hall of Buseoksa Temple, Korea.

4) Ministry of Culture (1989) An actual survey report of Magoksa, Korea.

5) Ministry of Culture (2004) A report on the repair of Daeungjeon hall of Bulgapsa temple, Korea.

6) Youngchukchongrim, (1997) Actual survey report on Daeungjeon Hall of Tongdosa temple and the Pagoda for Buddha's bones, Tongdosa.

7) Cho Eun Kyung, Han Joo Sung, (2010) A study on the constitution of Toekan and Asymmetrical Structure in Buddhist Pavilion, Journal of the Architectural Institute of Korea, June 2010, Vol. 26. No.4. Architectural Institute of Korea.

8) Lee Woo Jung, (2000) A study on the framework and arrangement of interior columns in single-story Buddhist halls, Master Dissertation, Graduate school of Seoul National University. 